\title{
CubeSat active thermal management in support of cooled electro-optical instrumentation for advanced atmospheric observing missions
}

L. Anderson, C. Swenson, R. Davidson, A. J. Mastropietro, E. Maghsoudi, et al.

L. Anderson, C. Swenson, R. Davidson, A. J. Mastropietro, E. Maghsoudi, S. Luong, S. Cappucci, I. Mckinley, "CubeSat active thermal management in support of cooled electro-optical instrumentation for advanced atmospheric observing missions," Proc. SPIE 10769, CubeSats and NanoSats for Remote Sensing II, 1076907 (18 September 2018); doi: 10.1117/12.2321959

EviE Event: SPIE Optical Engineering + Applications, 2018, San Diego, California, United States 


\title{
CubeSat Active Thermal Management in support of cooled electro- optical instrumentation for advanced atmospheric observing missions
}

\author{
L. Anderson ${ }^{a}$, C. Swenson ${ }^{\mathrm{a}}$, R. Davidson ${ }^{\mathrm{a}}$, A.J. Mastropietro ${ }^{\mathrm{b}}$, E. Maghsoudi ${ }^{\mathrm{b}}$, S. Luong ${ }^{\mathrm{b}}$, S. \\ Cappuccib $^{\mathrm{b}}$ I. Mckinley \\ a'Utah State University, 4130 Old Main Hill, Logan, UT, USA 84321; ' Jet Propulsion Laboratory, \\ California Institute of Technology, 4800 Oak Grove Dr, Pasadena, CA, 91109
}

\begin{abstract}
The need for advanced cooled electro-optical instrumentation in remote observations of the atmosphere is well known and demonstrated by SABER on the TIMED mission. The relatively new use of small satellites in remote earth observing missions as, well as the challenges, are epitomized by the upcoming NOAA EON-IR 12U CubeSat missions. These advanced CubeSat missions, which hope to accomplish scientific objectives on the same scale as larger more traditional satellites, require advanced miniaturized cryocoolers and active methods for thermal management and power control. The active CryoCubeSat project (ACCS) is a demonstration of such a technology. Utilizing Ultrasonic Additive Manufacturing (UAM) techniques, a Mechanical Pumped Fluid Loop (MPFL), and miniature pumps and cryocoolers to create a closed loop fluid-based heat interchange system. The ACCS project creates a two-stage thermal control system targeting $6 \mathrm{U}$ CubeSat platforms. The first stage is composed of a miniature Ricor K508N cryocooler while the second is formed by a UAM fabricated heat exchanger MPFL system powered by a micro TCS M510 pump. The working fluid is exchanged between a built-in chassis heat exchanger and a deployable tracking radiator. This work details the theory design and testing of a relevant ground-based prototype and the analysis and modeling of the results as well as the development of a design tool to help in customized active thermal control designs for small satellites. Ultimately, the ACCS project hopes to enable a new generation of advanced CubeSat atmospheric observing missions.
\end{abstract}

Keywords: Active Thermal Control, Mechanically Pumped Fluid Loop, Micro-Pump, Cryocooler, Ricor K508N, Ultrasonic Additive Manufacturing, SABER-Lite, CubeSat, SmallSat, Remote Sensing

\section{INTRODUCTION}

The use of CubeSats for remote sensing of the earth and its atmosphere is well established ${ }^{1}$. Planet Labs ${ }^{2}$ with more than 175 CubeSats has successfully created a global constellation capable of visibly mapping the planet on a daily basis. CubeSats and instrumentation capable of remote viewing outside the visible spectrum, specifically the infrared region, are also becoming common. An example of this is the upcoming National Oceanic and Atmospheric Administration (NOAA) EON-IR ${ }^{3}$ missions under development with the Jet Propulsion Laboratory (JPL). These missions hope to mitigate gaps in sounder data of temperature and water vapor profiles in the lower troposphere for afternoon polar orbits. Another example is the possible SABER-Lite ${ }^{4}$ mission which hopes to replace the aging SABER instrument on the TIMED mission with a constellation of CubeSats dedicated to monitoring the energetics, dynamics, and chemistry of the atmosphere in the 1.27 to 17 micro meter range ${ }^{5}$. These CubeSats would utilize global limb viewing and miniaturized and dedicated instrumentation. However, expanding the remote sensing capabilities of a CubeSat to the infrared spectrum presents additional challenges. The IR spectrum requires subcooled electro-optical instrumentation and detectors. Something which often necessitates the use of dedicated cryocoolers which in turn creates a thermal management problem for the CubeSat.

Traditionally, CubeSats have managed thermal loads via passive methods. These include emissive surface coatings, conduction paths, body mounted radiators, and even heat pipe technologies. However, as CubeSat technology has advanced, power and thermal densities have increased as well. This has led to CubeSats capable of generating over $100 \mathrm{~W}$ of thermal power. At this level active methods of thermal control and management are needed. Additionally,

CubeSats and NanoSats for Remote Sensing II, edited by Thomas S. Pagano,

Charles D. Norton, Proc. of SPIE Vol. 10769, 1076907 - (c) 2018 SPIE

CCC code: $0277-786 \mathrm{X} / 18 / \$ 18 \cdot$ doi: $10.1117 / 12.2321959$ 
cryocoolers require power inputs on the order of a few Watts to tens of Watts. Therefore, to cryogenically cool a focal plane, instrument, or optics below $110 \mathrm{~K}$ a large thermal load is generated at the cryocooler rejection interface.

An example of an active thermal control technology targeted at CubeSat platforms is the Active CryoCubeSat (ACCS) project which has successfully developed an active thermal control subsystem capable of rejecting more than 60 Watts of thermal loading from within a CubeSat chassis while maintaining rejection temperatures of less than $30^{\circ} \mathrm{C}$. This thermal control system utilizes a two-stage architecture with the first stage consisting of a single phase Mechanically Pumped Fluid Loop ${ }^{6}$ (MPFL) circulating a low viscosity coolant between a dedicated cold plate heat exchanger internal to the CubeSat chassis and a deployed solar tracking radiator connected to the MPFL via a rotationally flexible rotary fluid joint. The second stage relies upon a dedicated micro tactical cryocooler, hard mounted to the heat exchanger, to deliver cryogenic cold tip cooling to the optics, instrument, or detector. The system is capable of on orbit temperature setpoint control and thermal load rejection via tuning and throttling of the MPFL working fluid between laminar and Turbulant flow regimes. This helps to dynamically control the system and when coupled with guard heaters and the nadir deployed solar tracking radiator help to actively and dynamically maintain temperatures while rejecting variable thermal loads from the mission and environment. The ACCS project has demonstrated its viability as a thermal management and control solution through relevant ground-based testing in a thermal vacuum chamber and raised the TRL of the ACCS active thermal control system from 3 to 5 (TBR).

Additive manufacturing techniques were used in the design and fabrication of the ACCS system. Specifically, Ultrasonic Additive Manufacturing ${ }^{7,8,9}$ (UAM) was used to embed the MPFL fluid channels directly into the chassis of the CubeSat. This simplified and miniaturized the system. UAM fabrication was used on the cold plate rejection heat exchanger, which could replace an external panel of a CubeSat, as well as the deployable, two-sided radiator. The ACCS system utilizes a TCS M510 10 micro pump as the driver for the MPFL and a Ricor K508 $\mathrm{N}^{11}$ miniature cryocooler as the second stage cryogenic thermal control. The working fluid is Novec $7000^{12}$, a low viscosity coolant. The overall capabilities of the ACCS system are apparent from the preliminary results discussed below. A conceptual diagram of the ACCS systems and its function is given below in figure 1. Further details on the design, modeling, and analysis of the ACCS is given in reference 4. The ACCS team hopes that the development of an active thermal control and management system targeted at CubeSat's will advance future missions and technologies in Small-Satellite remote viewing, earth science, helioscience, and deep space ${ }^{13}$.

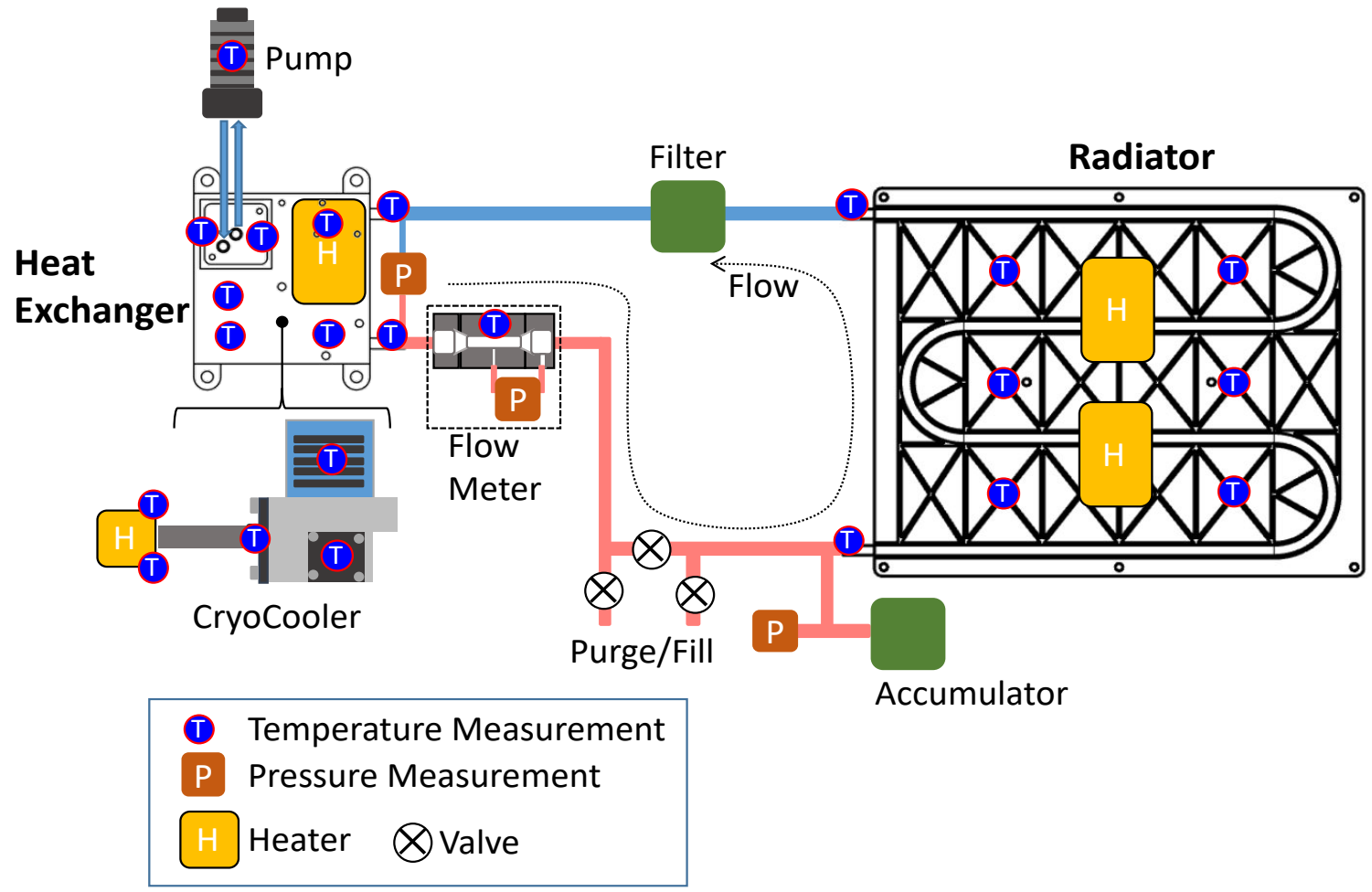

Figure 1. Systems diagram of the Active CryoCubeSat mechanically pumped fluid loop showing the operational concepts. 


\section{OBJECTIVES}

The ACCS projects primary objectives are summarized below in table 1. Essentially, the system is required to reject $30 \mathrm{~W}$ of thermal load while maintaining the rejection environment of the CubeSat below $30^{\circ} \mathrm{C}$. Restrictions on the size, weight, and required input power of the ACCS system are given as well. Note, that the ACCS system is designed as a $1 \mathrm{U}$ thermal control solution in that it will not take up more than a single standard unit within a CubeSat bus. The ACCS team has successfully operated the system at the required and objective performance goals with a series of preliminary tests, the results of which are given below. Future tests will sweep the system throughout its performance capabilities via discrete steps at specific states.

Table 1. Active CryoCubeSat grant objectives and requirements

\begin{tabular}{|c|c|c|}
\hline \multicolumn{3}{|c|}{ ACCS Project Objectives } \\
\hline 1) & \multicolumn{2}{|c|}{ Develop a miniature mechanically pumped fluid loop thermal control system for a CubeSat } \\
\hline 2) & \multicolumn{2}{|c|}{$\begin{array}{l}\text { Develop advanced manufacturing techniques using Ultrasonic Additive Manufacturing (UAM) and } \\
\text { Direct Metal Laser Sintering (DMLS) with aluminum to construct multifunctional structural-thermal } \\
\text { components of a CubeSat }\end{array}$} \\
\hline 3) & \multicolumn{2}{|c|}{ Demonstrate thermal accommodation of a miniature cryocooler suitable for a cryogenic instrument } \\
\hline \multirow{2}{*}{\multicolumn{3}{|c|}{$\begin{array}{ll}\text { Required Performance } & \text { Performance Goal }\end{array}$}} \\
\hline \multicolumn{2}{|c|}{ 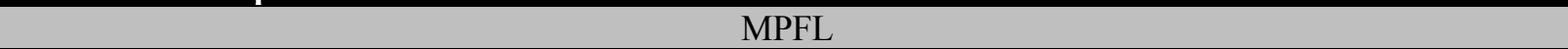 } & \\
\hline \multicolumn{2}{|c|}{$\begin{array}{l}\text { Thermal Load: }>30 \mathrm{~W} \\
\text { Interface: } 20-30^{\circ} \mathrm{C} \\
\text { Power: }<4 \mathrm{~W} \\
\text { Mass: }<2 \mathrm{~kg} \\
\text { Volume: }<1 \mathrm{U} \\
\text { Pointing: }<.005^{\circ} / \mathrm{s}\end{array}$} & $\begin{array}{l}\text { Thermal Load: }>60 \mathrm{~W} \\
\text { Interface: } 10-30^{\circ} \mathrm{C} \\
\text { Power: }<0.3 \mathrm{~W} \\
\text { Mass: }<0.5 \mathrm{~kg} \\
\text { Volume: }<0.3 \mathrm{U} \\
\text { Pointing: }<.0005^{\circ} / \mathrm{s}\end{array}$ \\
\hline \multicolumn{3}{|c|}{ Additive Manufacturing } \\
\hline \multicolumn{2}{|c|}{$10 \mathrm{~cm} \times 10 \mathrm{~cm}$ Heat Exchanger Panel } & $\begin{array}{l}10 \mathrm{~cm} \times 10 \mathrm{~cm} \text { Heat Exchanger Panel } \\
20 \mathrm{~cm} \times 30 \mathrm{~cm} \text { Radiator }\end{array}$ \\
\hline \multicolumn{3}{|r|}{ Cryocooler } \\
\hline \multicolumn{2}{|c|}{$\begin{array}{l}\text { Temperature: }<100 \mathrm{~K} \text { Thermal Load: }>50 \mathrm{~mW} \\
\text { Power: }<15 \mathrm{~W} \\
\text { Mass: }<1 \mathrm{~kg} \\
\text { Volume: }<1 \mathrm{U}\end{array}$} & $\begin{array}{l}\text { Temperature: }<75 \mathrm{~K} \text { Thermal Load: }>250 \mathrm{~mW} \\
\text { Power: }<5 \mathrm{~W} \\
\text { Mass: }<0.2 \mathrm{~kg} \\
\text { Volume: }<0.3 \mathrm{U}\end{array}$ \\
\hline
\end{tabular}

\section{EXPERIMENTAL DESIGN}

The ACCS system is currently designed for ground-based testing at Utah State University and utilizes the Center for Space Engineering's (CSE) Thermal Vacuum (TVAC) chamber. Each of the systems primary components as well as the necessary support structures, electronics and instrumentation are integrated into a self-contained test cube which can be inserted directly into the TVAC chamber for relevant environment testing. The radiator stack forms the bottom layer of the test cube. The radiator is suspended by Kevlar string attached to machine tuners which provide stiff structural support and good thermal isolation. The radiator is enclosed, top, bottom, and sides, with rigid copper subcooled shrouds. Liquid Nitrogen (LN2) is piped from an external tank through the vacuum chamber wall into flex tubes connected to brazed tubing on the copper shrouding. Black Z306 ${ }^{14}$ emissive paint is used on the inside of the shrouds and the surface of the UAM radiator to provide optimal surface properties for radiative transport. Custom made Multi-Layer Insulation (MLI) blankets are wrapped around the shrouds to mitigate thermal losses from the test cube, as a whole, to the cold rejection of the 
radiator stack. The LN2 cooling shrouds provide a realistic simulation of the deep space radiative environment of the radiator. The upper layer of the cube contains the heat exchanger assembly as well as an inline Venturi based flow meter, pressure transducers, an accumulator, and the electronics and instrumentation required to operate the ACCS system. The entire test is cube is wrapped in another MLI blanket to limit parasitic radiation from the chamber walls. PTFE, UHMW, and Kevlar are used throughout the system to thermally isolate the MPFL, heat exchanger, and the radiator from the support structures of the test cube and to limit any parasitic thermal leaks within the system which might affect the results and cause the system to deviate from the ideal case. Figure 2 shows the completed ACCS test cube on the benchtop and inside the USU/CSE TVAC chamber.
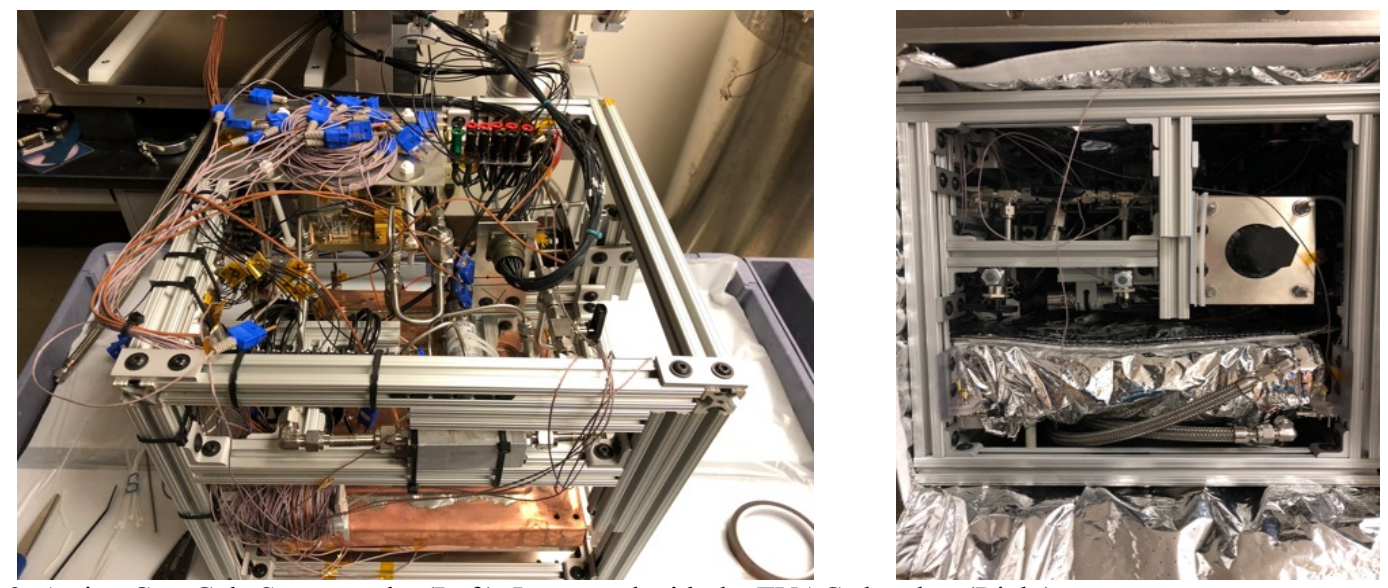

Figure 2. Active CryoCubeSat test cube (Left). Integrated with the TVAC chamber (Right).

The Ricor cryocooler and TCS micropump are surface and manifold mounted to the UAM heat exchanger which is in turn connected to the light weighted UAM radiator through stainless steel tubing, which forms the flow path for the MPFL and the working fluid. Surface mount and patch heaters are attached to the heat exchanger, the cryocooler cold tip, and the radiator to simulate additional operational or realistic environmental thermal loads. They also operate as a safety feature to ensure the system does not become too cold during testing. Figure 3 shows the light-weighted radiator, the CAD based modeling of the heat exchanger assembly, and the finalized prototype of the heat exchanger. The Ricor K508N was chosen due to its small size and light weight as well as it performance. The K508N is capable of rejecting more than 0.5 $\mathrm{W}$ while maintaining a cryogenic cold tip temperature of less than $110 \mathrm{~K}$. In addition, the cryocooler does not require more than $7.5 \mathrm{~W}$ of steady state input power. The TCS M510 pump was also selected due to its size and weight as well as its pumping power, pressure head, and compatibility with the Novec 7000 working fluid. Reference 4 details the design choices and methodology for both the micro pump and the cryocooler.
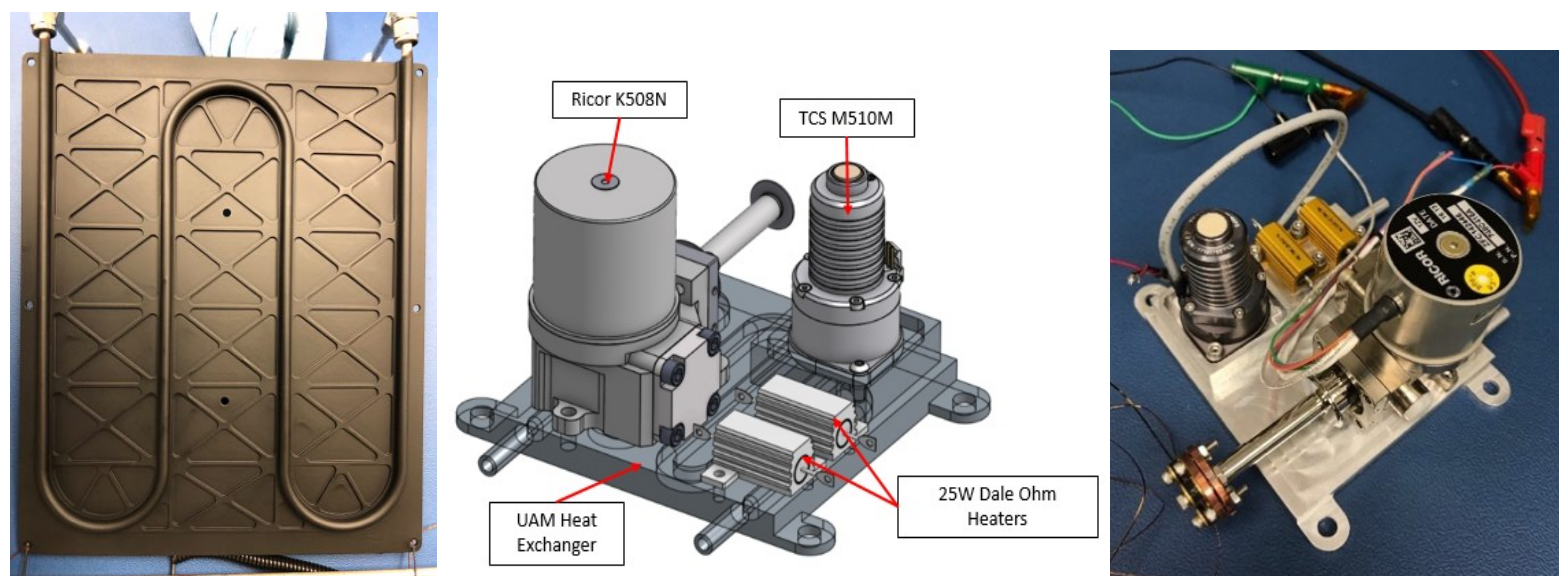

Figure 3. UAM light-weighted radiator (Right). CAD modeling of the heat exchanger system (Middle). Prototype heat exchanger assembly (Right). 


\section{INSTRUMENTATION, ELECTRONICS, AND SOFTWARE}

The instrumentation for the ACCS system is primarily focused on monitoring the thermal and flow behavior of the UAM heat exchanger, radiator, and MPFL as well as the Ricor K508N cryocooler and TCS M510 micro pump. Therefore, the test cube was instrumented with temperature sensors, voltage monitors, pressure transducers, and IR cameras. Temperature was measured by 30 type T thermocouples (TC). These TC's were laid out at key points on each of the primary components as well as in a grid pattern across the heat exchanger and radiator to help characterize the thermal distribution within the primary heat transfer regions. Four emersion type thermocouples monitor the inlet and outlet fluid temperatures of the working fluid for the heat exchanger and radiator. The cryogenic temperature of the cold tip was measured by two Lakeshore DT $670^{15}$ RTD temperature sensors bolted onto the cold tip copper mass. The power delivered to each of the heaters, the pump, and the cryocooler were monitored with dedicated current sensors and voltage dividers. The absolute static pressure of the MPFL and the differential pressure across the pump/heat exchanger were monitored by HoneyWell pressure transducers. The flow rate of the MPFL was continuously monitored with an inline custom-made Venturi type flow meter and a second HoneyWell pressure transducer. Finally, two FLIR Lepton ${ }^{16}$ thermal IR cameras were used to visually monitor the analog temperature distribution across the bottom of the heat exchanger and the cryocooler and micro pump mounted on top.

The ACCS test cube required a custom-made electronics box to support each of the subsystem components. This included power monitors for the heaters, pump, and cryocooler as well as sensors for the temperature, flow rate, RPMS's and pressure. The pump and cryocooler also required drive and control electronics. Figure 4 shows the E-box for the characterization of the ACCS system. LabVIEW was used as the primary measurement and control software for the ACCS test cube. Coupled with a National Instruments CompactDAQ ${ }^{17}$ the ACCS team was able to develop a dedicated measurement and control program which continuously monitored the ACCS test cube while in the TVAC chamber. Basic Feedback and control logic was also implemented to help ensure that the test cube never left acceptable performance bounds and that any collected data was saved to multiple locations for redundancy.

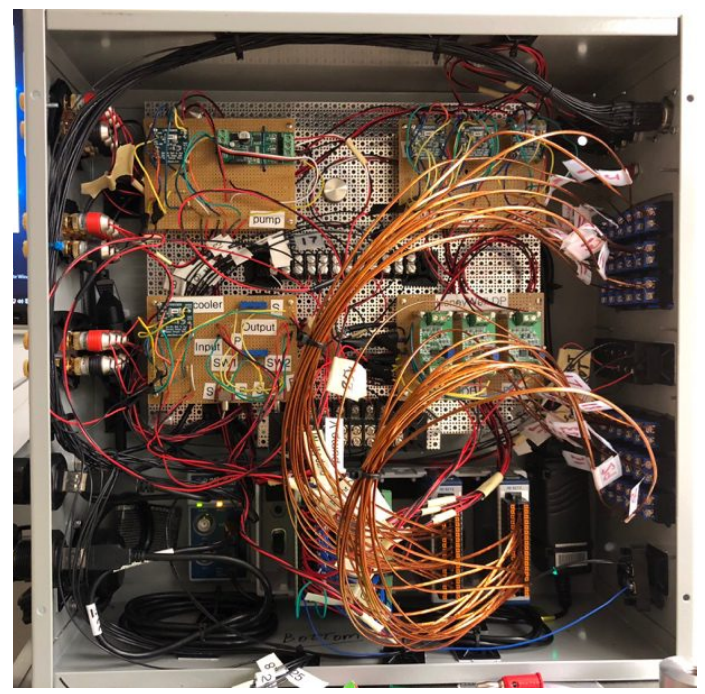

Figure 4. Active CryoCubeSat custom electronics and instrumentation E-box.

\section{MODELING AND ANALYSIS}

Two distinct analysis tools were developed and used for the design and testing of the ACCS project. The first was a series of excel spreadsheet-based tools developed from the basic mathematical principles of heat transfer and fluid dynamics. These tools allowed for the rapid study of conceptual mission designs. Tools like these are often used by teams employing concurrent engineering methodologies. From these basic principles, the team was able to clearly define the behavior of the system and the thermal relationship between each of the key components. By using these excel tools, the team was able to quickly design the ACCS MPFL, heat exchanger, and radiator. Once the team had developed a complete 
design, Thermal Desktop ${ }^{18}$ was used to develop a rigorous numerical model of the system. This included the analysis of the non-linear PID based thermal distribution across the radiator and heat exchanger.

By first designing the system from basic principles the team was able to rapidly refine a design and concept of operation. Once that design was set, Thermal Desktop could be used to refine and verify the design. Future publications will focus on the correlations between the experimental results of the ACCS system and the analysis/modeling. For more information see reference 4 .

\section{EXPERIMENTAL TESTING PROCEDURE}

The testing of the ACCS system occurred in a relevant TVAC environment. First the integrated test cube, wrapped in MLI, was placed into the TVAC chamber. Data cabling, power lines, and LN2 flex lines were all connected via feedthroughs. Next a vacuum of at least $\mathrm{e}^{-5} \mathrm{mbar}$ was pulled on the system. Once a sufficient and stable vacuum was achieved, LN2 was pumped into the radiator cooling shrouds and the temperature of the radiator stack was slowly ramped down to less than $92 \mathrm{~K}$. The flow of LN2 and the setpoint temperature of the shrouds was controlled by an Omega I series PID controller and a dedicated thermocouple attached to the top LN2 cooling shroud. Once the system reached a steady state working temperature a predefined series of testing procedures was executed. These preliminary procedures were aimed at outlining the basic performance metrics of the ACCS system as well as the maximum and minimum thermal loads. The flow rate of the Novec-7000 working fluid was varied from a high Reynolds number turbulent regime $(\mathrm{Re}=\sim 7400$, flow rate $\sim 850 \mathrm{~mL} / \mathrm{min}$ ) to a slower transitional, but still turbulent flow regime $(\mathrm{Re}=\sim 3000$, flow rate $\sim 350$ $\mathrm{mL} / \mathrm{min}$ ) for each of the given setpoints. It should be noted that the Ricor K508N cryocooler was set to $12 \mathrm{~V}$ while its internal controller dynamically varied the power to an average of about $6 \mathrm{~W}$. Therefore, each of the given test setpoints of table 2 have the dynamically varying power of the cryocooler added to them. Figure 5 shows a detailed breakout of the thermal loads applied to the ACCS system as well as the steady state total loads for an example preliminary test run.

Table 2. Active CryoCubeSat preliminary testing procedure

\begin{tabular}{|l|l|l|l|l|}
\hline \multicolumn{4}{|c|}{ ACCS Preliminary Testing Procedure } \\
\hline 1 & Pull a vacuum of at least 5xe ${ }^{-5}$ mbar: To prevent convective heat transfer \\
\hline 2 & Cool the LN2 shrouds to below 90 K & High Reynolds \#: 7400 \\
\hline 3 & HX Power: $20 \mathrm{~W}$ & $\begin{array}{l}\text { Pump Power: } \sim 10 \mathrm{~W} \\
\text { Cryocooler Power: } \sim 6 \mathrm{~W}\end{array}$ & Cold Tip Power: 0.25 W & Test \\
\hline 4 & HX Power: $30 \mathrm{~W}$ & $\begin{array}{l}\text { Pump Power: } \sim 1.5 \mathrm{~W} \\
\text { Cryocooler Power: } \sim 6 \mathrm{~W}\end{array}$ & Cold Tip Power: 0.25 W & Lower Reynolds \#: 3000 \\
\hline 5 & HX Power: $35 \mathrm{~W}$ & $\begin{array}{l}\text { Pump Power: } \sim 10 \mathrm{~W} \\
\text { Cryocooler Power: } \sim 6 \mathrm{~W}\end{array}$ & Cold Tip Power: 0.25 W & High Reynolds \#: 7400 \\
\hline 6 & HX Power: $45 \mathrm{~W}$ & $\begin{array}{l}\text { Pump Power: } \sim 1.5 \mathrm{~W} \\
\text { Cryocooler Power: } \sim 6 \mathrm{~W}\end{array}$ & Cold Tip Power: 0.25 W & Lower Reynolds \#: 3000 \\
\hline 7 & $\begin{array}{l}\text { HX Power: } 20 \mathrm{~W} \\
\text { Rad. Power 30 W }\end{array}$ & $\begin{array}{l}\text { Pump Power: } \sim 10 \mathrm{~W} \\
\text { Cryocooler Power: } \sim 6 \mathrm{~W}\end{array}$ & Cold Tip Power: 0.25 W & High Reynolds \#: 7400 \\
\hline 8 & $\begin{array}{l}\text { HX Power: } 30 \mathrm{~W} \\
\text { Rad. Power: } 30 \mathrm{~W}\end{array}$ & $\begin{array}{l}\text { Pump Power: } \sim 1.5 \mathrm{~W} \\
\text { Cryocooler Power: } \sim 6 \mathrm{~W}\end{array}$ & Cold Tip Power: 0.25 W & Lower Reynolds \#: 3000 \\
\hline 9 & HX Power: $50 \mathrm{~W}$ & $\begin{array}{l}\text { Pump Power: } \sim 10 \mathrm{~W} \\
\text { Cryocooler Power: } \sim 6 \mathrm{~W}\end{array}$ & Cold Tip Power: 0.25 W & High Reynolds \#: 7400 \\
\hline 10 & HX Power: $20 \mathrm{~W}$ & $\begin{array}{l}\text { Pump Power: } \sim 10 \mathrm{~W} \\
\text { Cryocooler Power: } \sim 6 \mathrm{~W}\end{array}$ & Cold Tip Power: 0.5 W & High Reynolds \#: 7400 \\
\hline
\end{tabular}



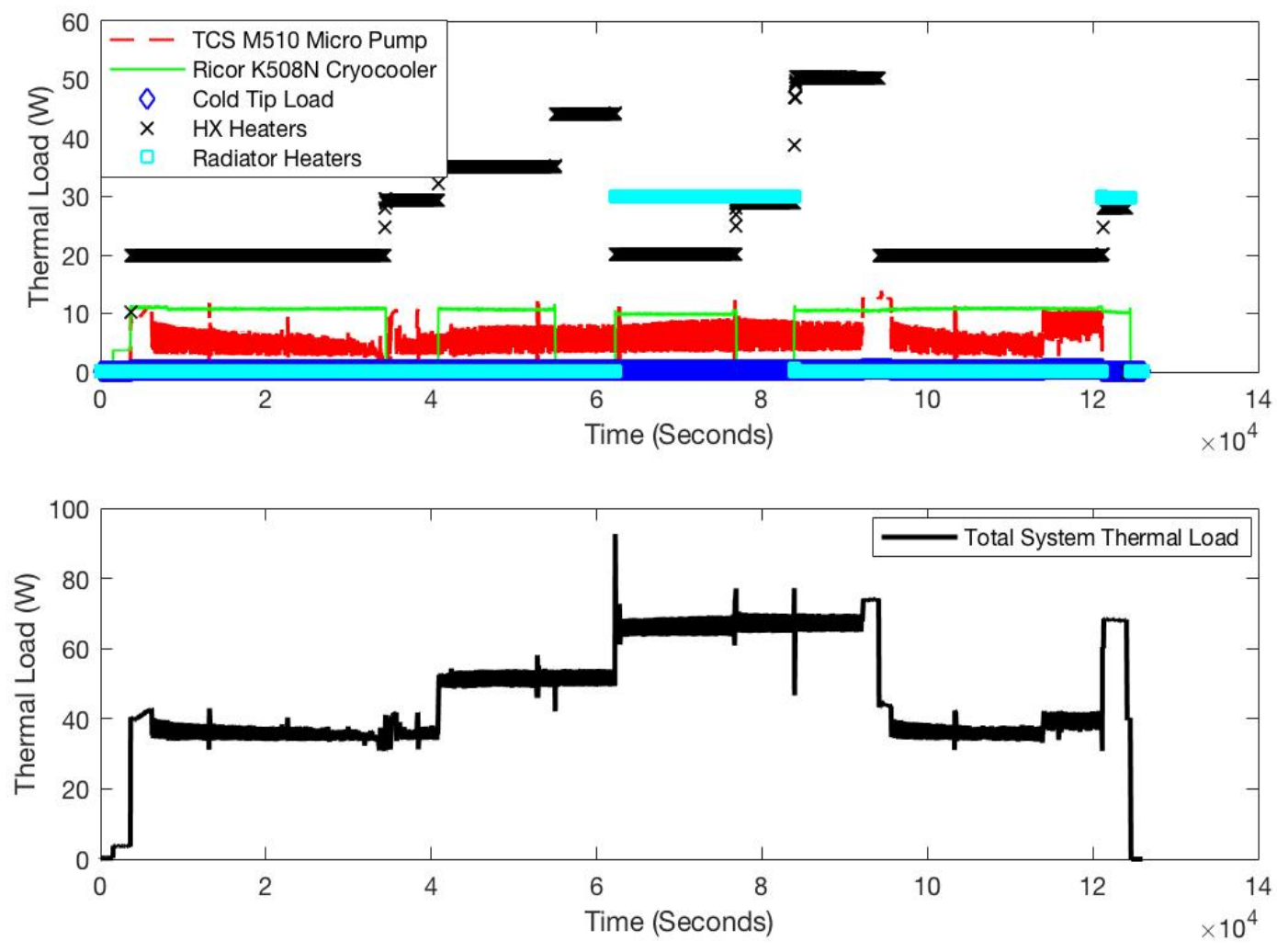

Figure 5. Piecewise and total system thermal loading for the example test run of Table 2.

\section{PRELIMINARY RESULTS}

The ACCS results discussed below are preliminary and require additional testing to be considered a full characterization of the system. Four consecutive and complimentary preliminary test runs are presented below. Figure 6 represents the variations in average and steady state temperature of the UAM heat exchanger, Ricor K508N cryocooler, and UAM radiator with respect to time and flow rate for each of the thermal loads given in Table 2 . The data indicates that the heat exchanger operates at a minimum temperature of approximately $-5^{\circ} \mathrm{C}$ at $35 \mathrm{~W}$ and can maintain temperatures of $<30{ }^{\circ} \mathrm{C}$ for thermal loads $>65 \mathrm{~W}$. Which validate the objectives of Table 1 . The temperature gradients within the ACCS MPFL are such that the heat exchanger operates at the hot end of the system, while the radiator forms the cold sink. The cryocooler which is surface mounted to the radiator operates, on average, $10{ }^{\circ} \mathrm{C}$ above the temperature of the heat exchanger, which is appropriate due to conduction gradients within the heat exchanger and cryocooler. The monitored temperatures of the cryocooler include: the Ricor K508N's cold finger and body interface, the piston housing, and the motor casing. Based on both the heat exchanger and cryocooler average temperature, the ACCS system is able to maintain an appropriate working environment for the cryocooler at each of the given steady state thermal load values. The radiator operates at approximately $\sim 20{ }^{\circ} \mathrm{C}$ colder than the heat exchanger. This indicates that the thermal gradients within the radiator are larger and more complex than were expected by the preliminary modeling. Further work on the modeling and characterization of the radiator will be required. The effect of throttling the working fluids flow rate on the temperatures of the system are called out in figure 6. The ACCS system was pre-charged to a static absolute pressure of $>60$ psi to prevent cavitation of the Novec-7000 during operation. Figure 7 demonstrates the interdependent relationship between the static pressure of the system and the temperature of the working fluid.

The ACCS MPFL creates a steady state balance between the inputted thermal power and the temperature of the UAM radiator and heat exchanger. Therefore, by measuring the fluid inlet and outlet temperatures of both the radiator and 
heat exchanger, and with knowledge of the flow rate of the working fluid, the specific heat transfer rate of the system can be calculated. Figure 8 compares the total thermal power inputted to the system at each of the steady state points of Table 2 and the subsequent thermal power absorption of the heat exchanger and rejection of the radiator. The data shows that the thermal energy balance between the two is nearly identical. This indicates that the ACCS MPFL system is thermally well isolated and that nearly all the inputted thermal power of the system is absorbed and rejected by the UAM heat exchanger and radiator.
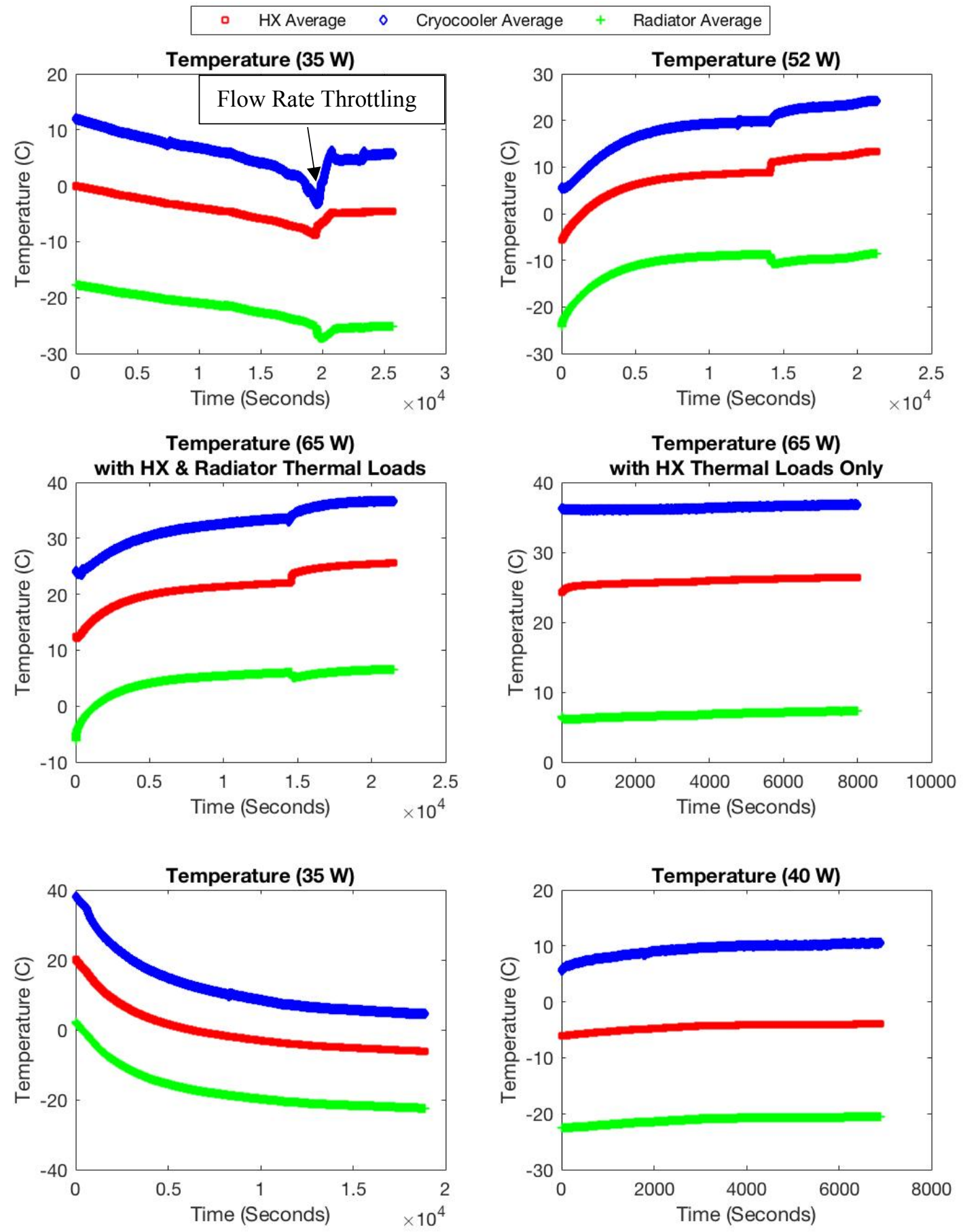

Figure 6. Average temperature of the heat exchanger, cryocooler, and radiator for each steady state thermal load setpoint. 


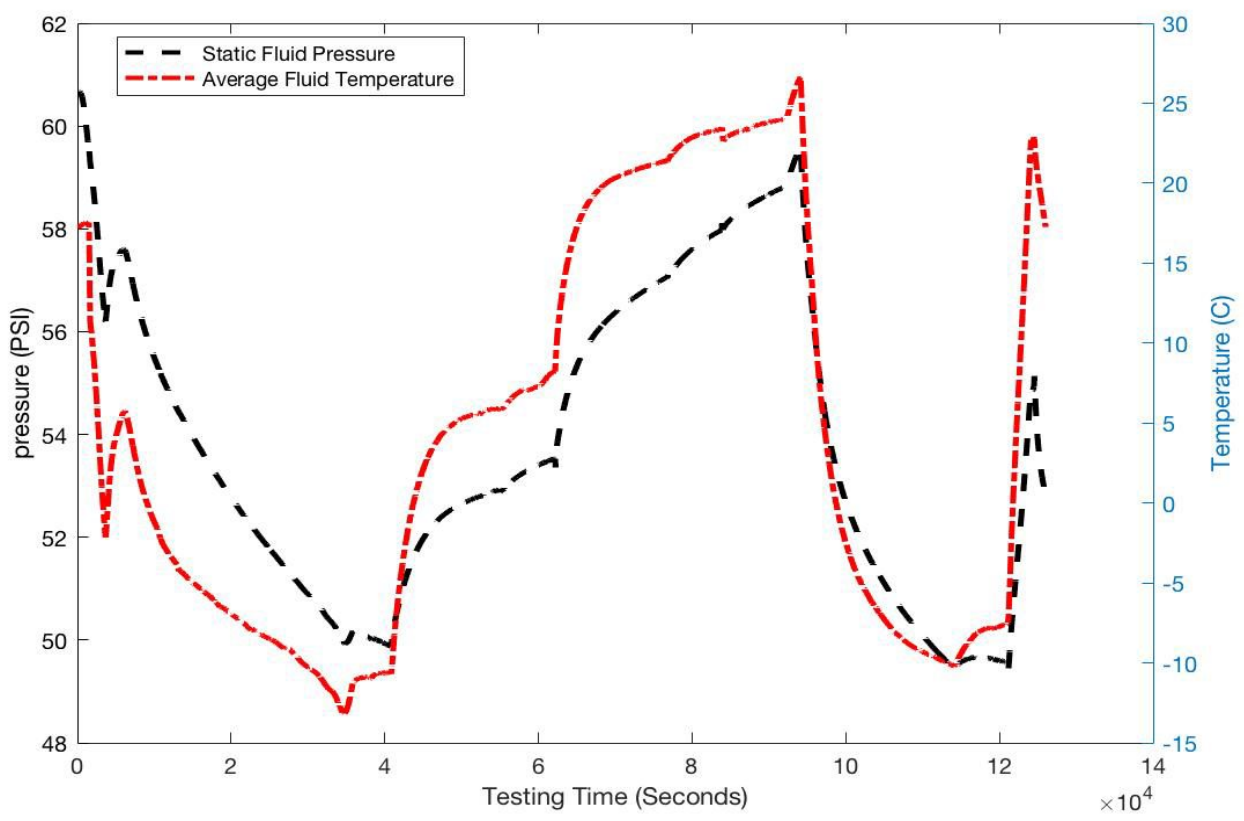

Figure 7. Static pressure of the ACCS working fluid with respect to time and temperature. Note, the system was precharged to $\sim 67$ psi prior to testing.
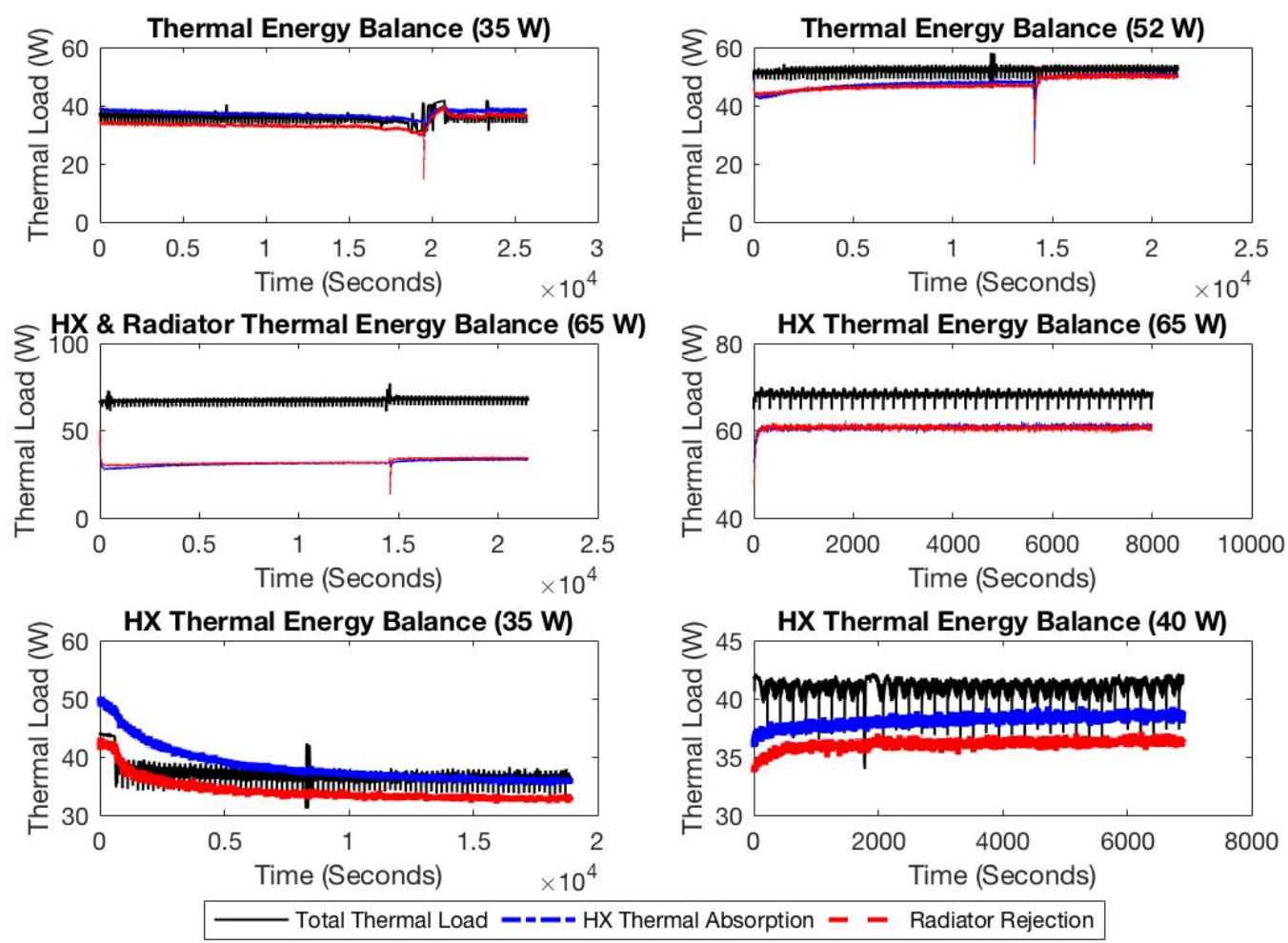

Figure 8. The thermal energy balance (Absorption/Rejection) of the ACCS's heat exchanger and radiator vs. total inputted thermal power. 
It should be noted that for the case of thermal energy being generated on both the heat exchanger and radiator, via surface mount heaters, the overall temperature of the system increases and the steady state balance between temperature and thermal energy is consistent with the systems overall linear trend. However, the additional energy on the radiator is simply rejected and does not contribute significantly to the specific energy transfer of the whole system. Small differences between the total inputted power and the thermal energy are due to the variable efficiencies of the pump and cryocooler as well as power drops in the systems electronics and wiring.

The TCS M510 provides a governed \& controlled flow rate in that changes in the density, viscosity, or temperature of the system have little effect on the outputted flow rate. The working fluid Novec-7000 was pumped at the two distinct flow rates described in the test procedure $(\operatorname{Re}=\sim 7400$, flow rate $\sim 850 \mathrm{~mL} / \mathrm{min}) \&(\mathrm{Re}=\sim 3000$, flow rate $\sim 350 \mathrm{~mL} / \mathrm{min}$ ). These flow rates and the subsequent pump RPM's are shown below in figure 9 . The data shows that the pump does indeed provides a fairly stable flow rate. It should be noted that the data for the lower flow rate values was compared to the Venturi meter's calibration curve and adjusted via the pump affinity laws ${ }^{19}$. The differential pressure drop for the pump was measured from the inlet to the outlet of the heat exchanger. This pressure drop ranges from a high flow rate value of $\sim 2.7 \mathrm{psi}$ to a low flow rate of $\sim 0.45 \mathrm{psi}$ and is temperature dependent. In addition, the data of figure 10 shows that the heat exchanger is consistently warmer than the pump. This makes physical sense when considering the fact that the pump is cooled by the liquid flowing through it. This is also consistent with the direction of the systems thermal gradient i.e. with the heat exchanger absorbing thermal energy and transferring it to the radiator.

A comparison of the pressure drops experienced across the pump/heat exchanger for the given flow rates is shown below in figure 11 and compared to a $2 \mathrm{k}$ model based upon the modified Bernoulli relationship between pressure and flow rate. This model is used to calculate the overall pressure drop of the system vs. flow rate. As can be seen the experimental results match the expected analytical results closely. This comparison is a validation of the fluid flow modeling done by the ACCS team prior to the design and physical engineering of the experimental MPFL test bed.
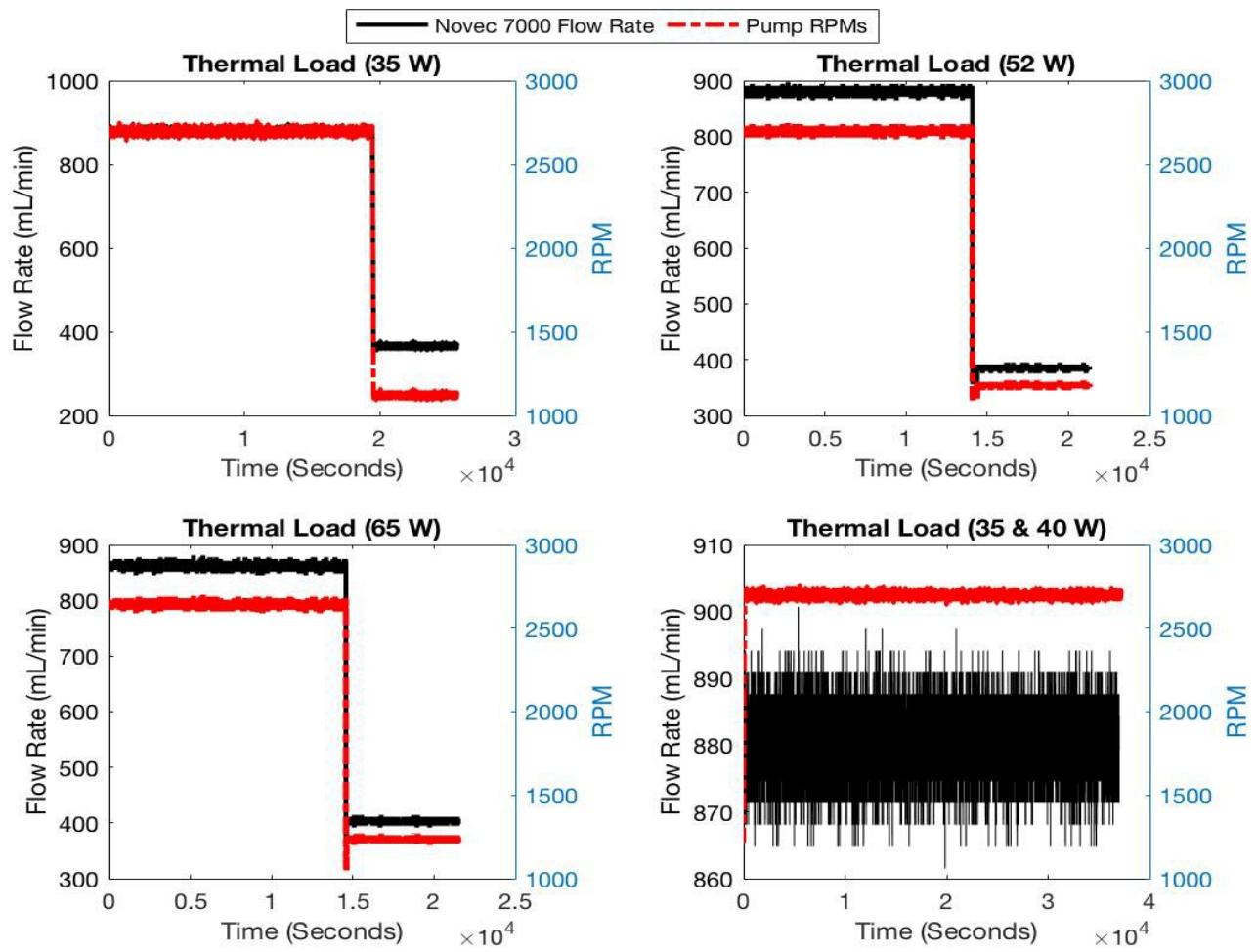

Figure 9. Flow rate of Novec-7000 working fluid and RPM's of the TCS M510 micro pump. 

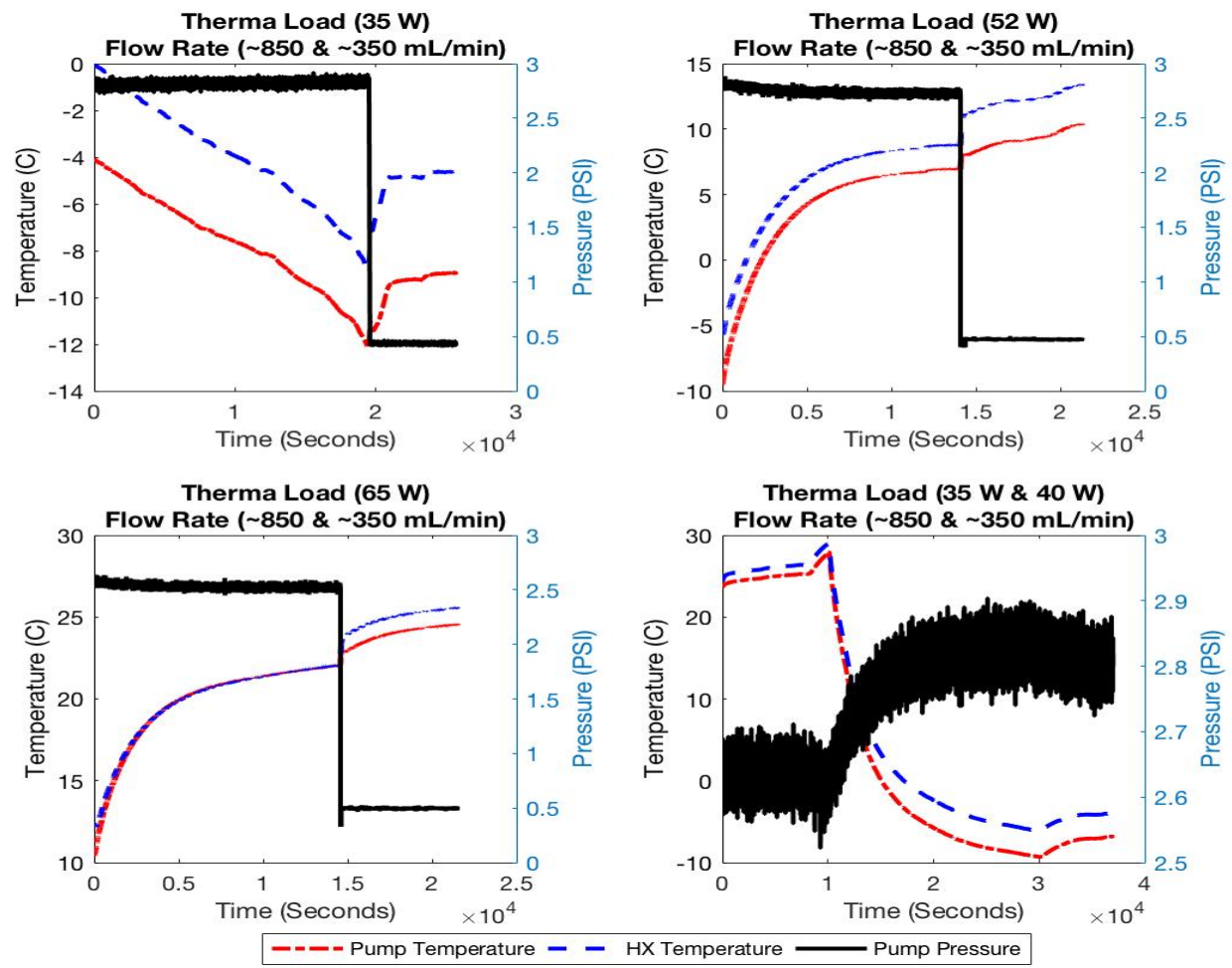

Figure 10. Temperature, rejection environment temperature, and differential pressure of the TCS M510 micropump for the ACCS system at each tested steady state thermal load

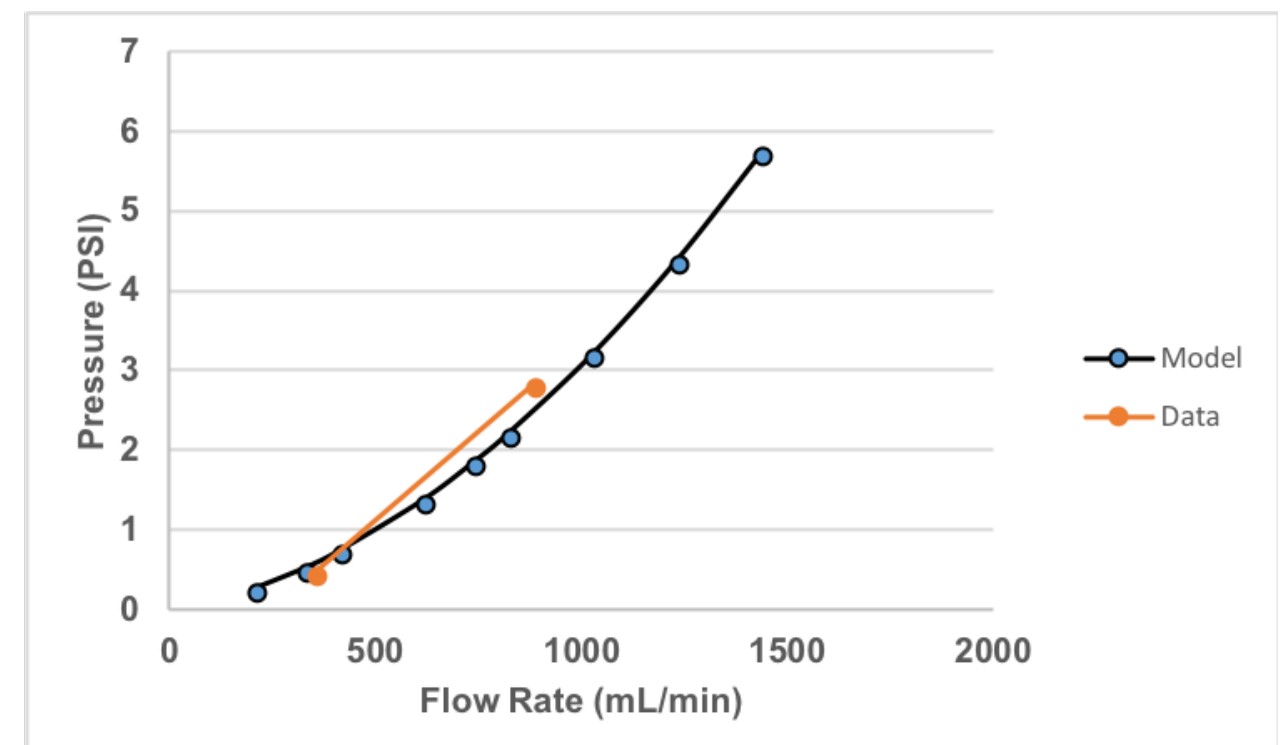

Figure 11. Modified Bernoulli model (wt. 2k method) of the pressure drop within the ACCS system. Compared to preliminary pressure drop data. 
The cold tip of the Ricor K508N cryocooler was pre-set to approximately $\sim 110 \mathrm{~K}$ for the duration of the preliminary test runs. The cryocooler operates on a dedicated feedback and control loop and was able to maintain, with the ACCS system continuously rejecting its working power, the given setpoint for each of the thermal loads. This demonstrates that the cryocooler can sustain subcooled cold tip temperatures for instrumentation, optics, and detectors for remote viewing despite variations in the thermal load of the CubeSat environment, mission requirements, or CubeSat electronic/instrument loading. Figure 12 shows the variation in cold tip temperature $(<110 \mathrm{~K})$ for the entire example test run. The deviation in the average temperature of the cryocooler and its required input power as a function of the variation in the rejection temperature of the heat exchanger are shown in figure 14. It can be seen that, in general, the average temperature of the cryocooler and the power required to reject the cold tip load and maintain the cryogenic setpoint increase with comparable increases in the heat exchanger rejection temperature. This result is not surprising and consistent with the overall thermal gradients of the ACCS system and the working ambient environment requirements of cryocoolers.

\section{Cryocooler Cold Tip Temperature}

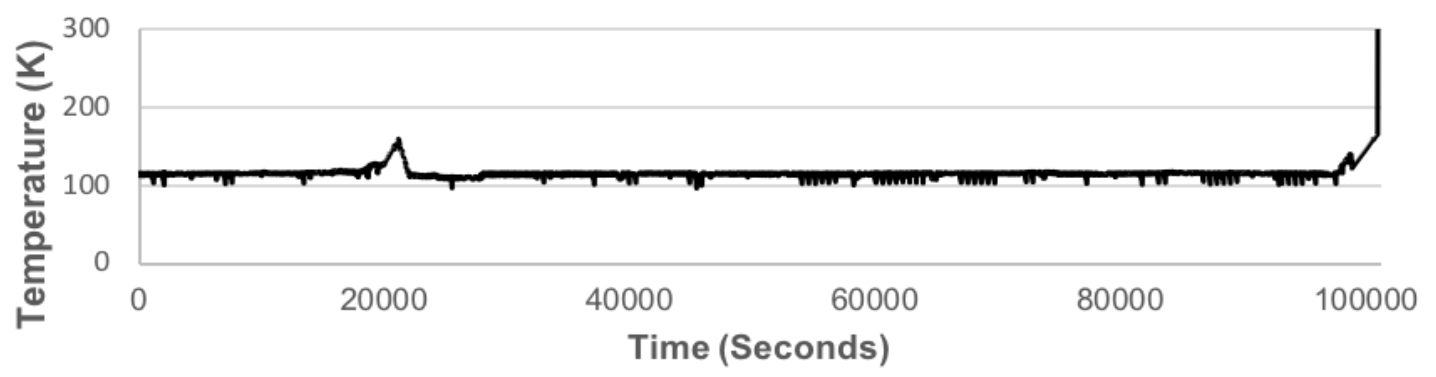

Figure 12. Ricor K508N cryocooler cold tip temperature. Cold tip setpoint $\sim 100 \mathrm{~K}$ with a variable thermal load of $0.25 \mathrm{~W}$ to $0.5 \mathrm{~W}$

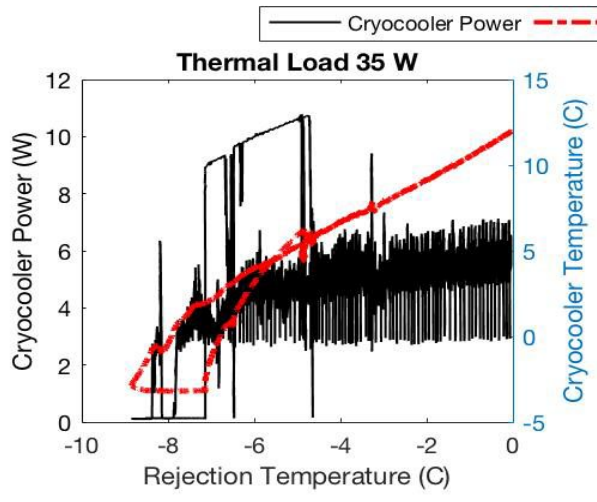

Average Cryocooler Temperature
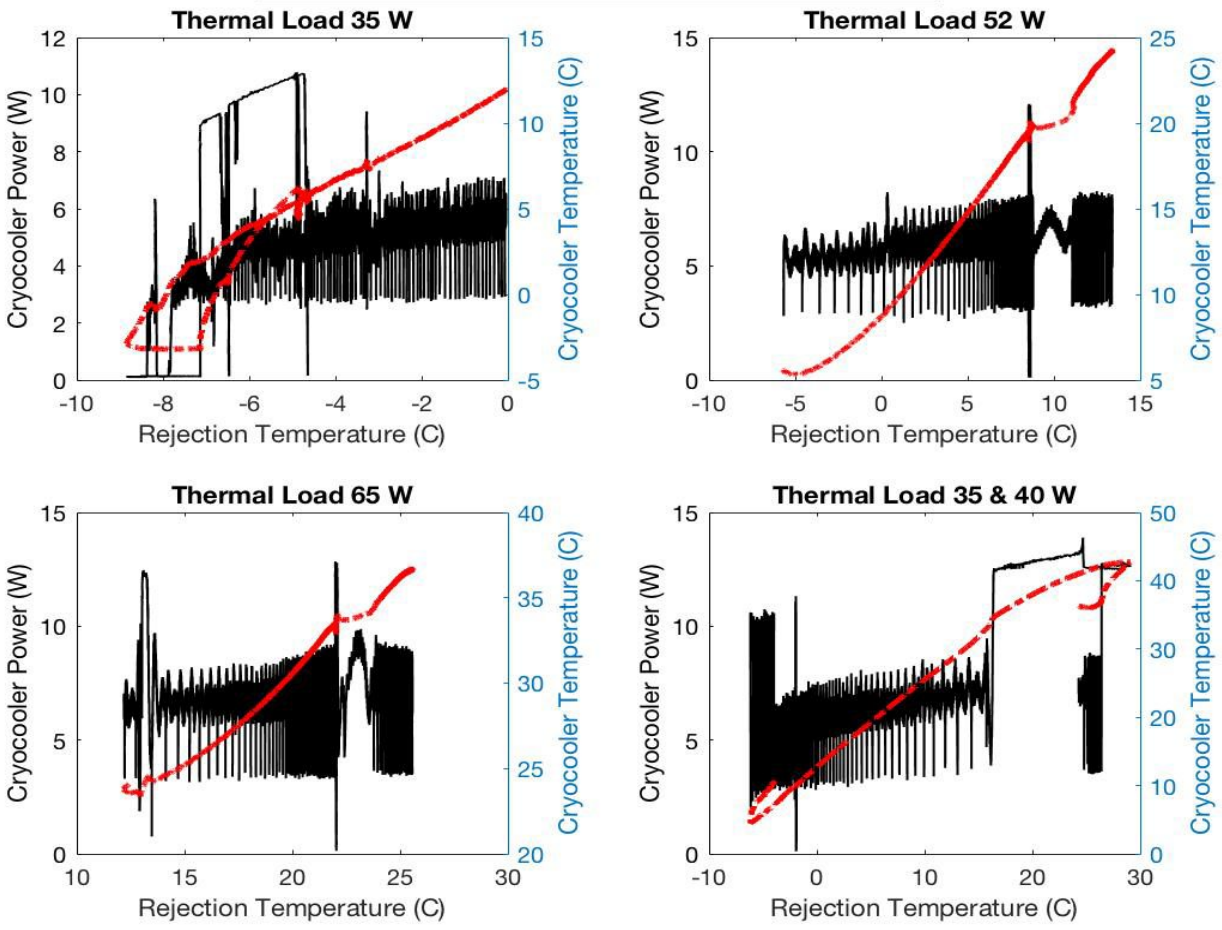

Figure 13. Ricor K508N cryocooler input power and temperature with respect to cold plate (HX) rejection temperature. 
The performance of the ACCS system is presented in Figure 14 which graphs the total steady state thermal load vs. average cold plate heat exchanger rejection temperature. These results were collated from each of the four preliminary test runs and demonstrate the overall abilities of the ACCS active thermal control subsystem to manage the thermal loads generated by a CubeSat or instrument. The results show that the system is capable of rejecting more than $65 \mathrm{~W}$ of steady state thermal power while maintaining the heat exchanger rejection temperature at less than $30^{\circ} \mathrm{C}$. An interesting point is that the differences in performance between the laminar and turbulent flow cases are often less than $5^{\circ} \mathrm{C}$. Therefore, it can be concluded that a lower laminar flow rate could be used as the standard working point for the system. This would save on the required power for the active system as well as simplifying the design and implementation of the system. The results also show that when the thermal load is shared between the heat exchanger and the radiator, as in the case of radiative environmental loading, the temperature of the heat exchanger is less than if the entire load is internal to the CubeSat and heat exchanger alone. Finally, if the cold tip load is increased from $0.25 \mathrm{~W}$ to $0.5 \mathrm{~W}$ the cold tip temperature does not vary due to the dynamic control of the Ricor K508N cryocooler, however the required power of the cryocooler does increase. A thermal view of the HX is given in Figure 15, note the temperature distribution across the heat exchanger surface as well as the thermal variation in the pump and cryocooler. These results show that for the case of infrared remote viewing the ACCS system can maintain a suitable thermal environment on a CubeSat while supporting cryogenic cooling for onboard instrumentation.

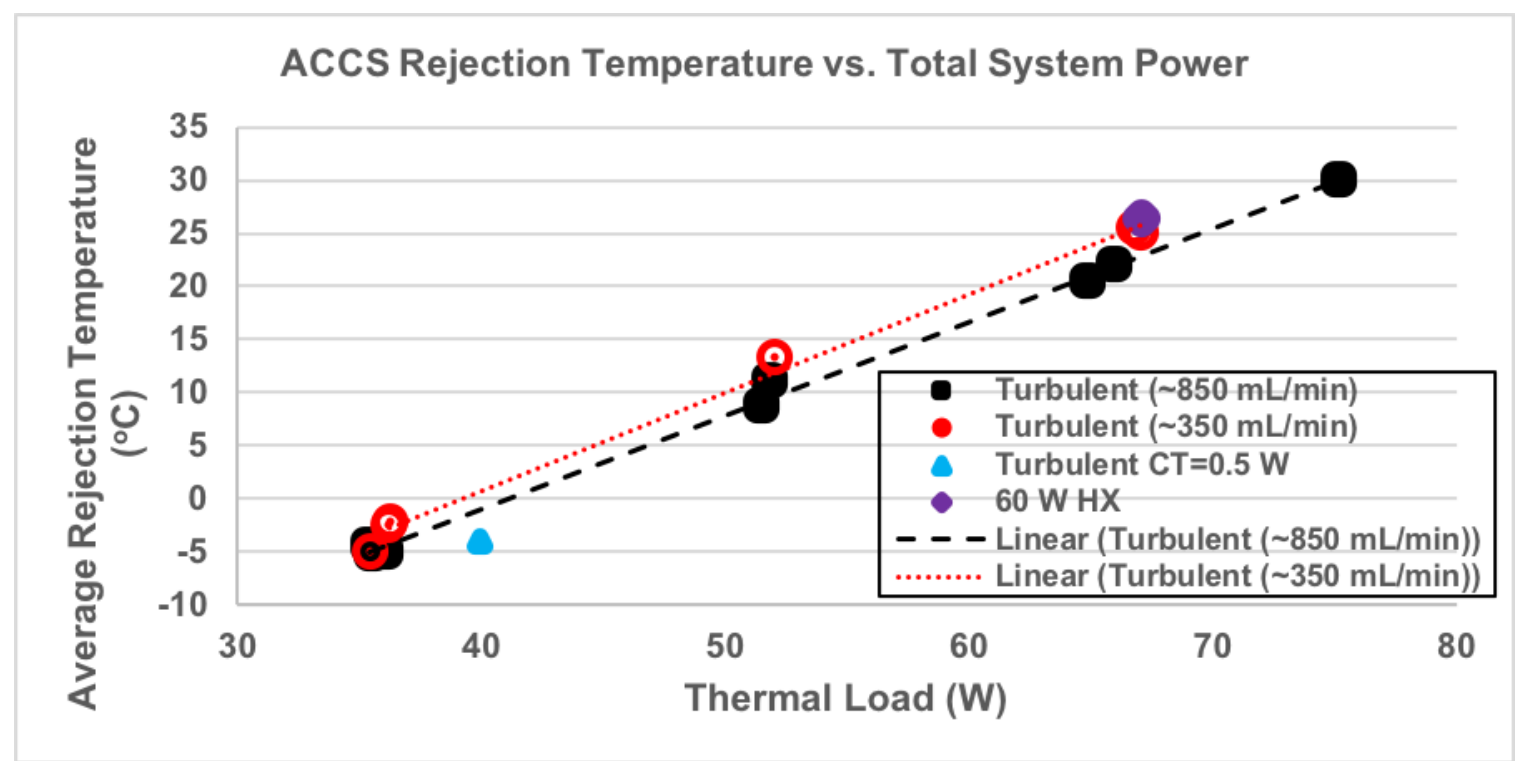

Figure 14. Overall performance of the ACCS system. Steady state temperature vs thermal load.
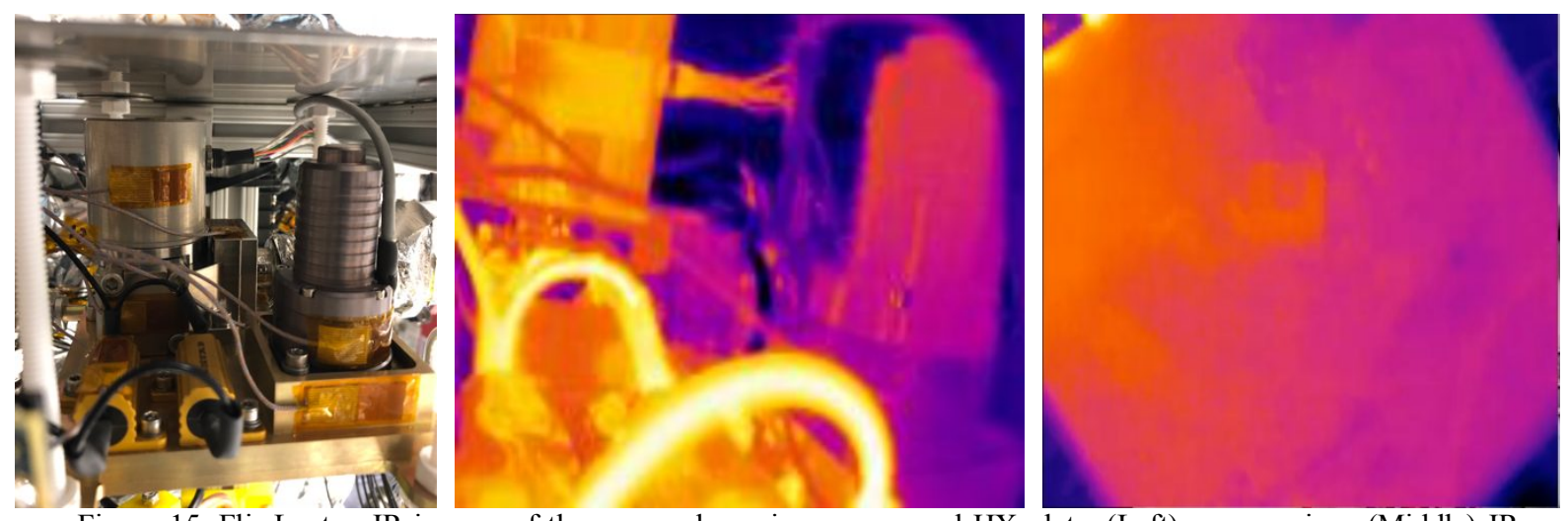

Figure 15. Flir Lepton IR images of the cryocooler, micro-pump, and HX plate. (Left) camera view. (Middle) IR camera view. (Right) Bottom of the HX plate 


\section{FUTURE WORK}

The ACCS project is still in the preliminary stages of testing and analysis. The system will require more testing to be considered fully characterized. The CSE team is also working with Dr. Randy Christenson of USU to develop a control and feedback algorithm for the ACCS MPFL to actively and dynamically vary the cold plate heat exchanger temperature as a function of flow rate and thermal loading. This work will allow the ACCS system to autonomously adjust its variable parameters to maintain the working environment of the CubeSat and instruments as the mission and space environment demand. In addition, a new grant has been secured by the team from NASA's Small Technology Partnership to develop and test a prototype deployable tracking radiator and thermal vibrational isolation system for the heat exchanger and cryocooler cold tip. The new grant will operate under the title Active Thermal Architecture for Cryogenic Optical Instrumentation (ATACOI) and will help to further the development of active thermal control technologies for SmallSats. Finally, the temperature and thermal distribution across the radiator is more complicated than was originally modeled by the team. To this end, additional Thermal Desktop numerical models are being developed to help understand the exact thermal mechanics at work within the UAM radiator structure.

\section{CONCLUSIONS}

The Active CryoCubeSat project has successfully developed and tested an active thermal management system targeted at CubeSats platforms. The ACCS team has demonstrated the prototype system in a relevant ground-based environment and shown that the active control system can maintain steady state temperatures of less than $30{ }^{\circ} \mathrm{C}$ with thermal loading of more than $65 \mathrm{~W}$. In addition, the cold plate heat exchanger can reject the thermal load of a Ricor K508N cryocooler and help it to maintain its cold tip temperature at less than $\sim 110 \mathrm{~K}$ with cold tip power loads between $0.25 \mathrm{~W}$ and $0.5 \mathrm{~W}$. These preliminary results indicate that all of the stated objectives and goals for the ACCS system have been met. Ultimately, the ACCS project hopes to enable a new generation of advanced CubeSat missions and instrumentation.

\section{ACKNOWLEDGMENTS}

The team would like to thank the NASA Small Spacecraft Technology Partnership office and the Jet Propulsions Laboratory as well as the Electrical and Computer Engineering Department at Utah State University for making this research possible. In addition, the ACCS project would not exist without the dedicated undergraduate research team of USU's Center for Space Engineering.

\section{REFERENCES}

[1] Howell, E. (June 2019) "CUBESATS: TINY PAYLOADS, HUGE BENEFITS FOR SPACE RESEARCH" https://www.space.com/34324-cubesats.html

[2] Planet Labs [Online] June 2018, https://www.planet.com/products/monitoring/

[3] Dan Mamula "NOAA EON-IR CubeSat Study for Operational Infrared Soundings" [Online] June 2018, https://digitalcommons.usu.edu/smallsat/2017/all2017/34/

[4] Lucas S. Anderson "The Active CryoCubeSat Project: Design and Status" [Online] June 2017, https://digitalcommons.usu.edu/smallsat/2017/all2017/154/

[5] SABER: A pioneer in atmospheric science [Online] June 2018, https://www.nasa.gov/centers/langley/news/factsheets/SABER.html

[6] Mastropietro, A. J., Bhandari, Pradeep, Birur, Gajanana, et. al., "Summary and Status of 5 Mechanical Pumped Fluid Loop (MPFL) Projects Currently in Process at the Jet Propulsion Laboratory (JPL) for the Planned Europa Mission, Mars 2020, Ecosystem Spaceborne Thermal Radiometer Experiment on Space Station (ECOSTRESS), Orbiting Carbon Observatory (OCO-3), and Cold Atom Lab (CAL)," Thermal and Fluids Analysis Workshop (TFAWS), Mountain View, CA, August 2016.

[7] Fabrisonic 3D Metal Printing Without Melting [Online] June 2018, fabrisonic.com

[8] Maghsoudi, Elham, Mastropietro, A. J., Roberts, Scott, and Kinter, Bradley, "Experimental Thermal Performance Comparison of 3D Printed Aluminum Heat Exchangers vs Traditionally Manufactured Heat Exchangers," Spacecraft Thermal Control Workshop (STCW), El Segundo, CA, March 2017.

[9] Mastropietro, A. J., Roberts Scott, Hofmann Douglas, Maghsoudi, Elham, and Luong, Simon, "NASA Development of Complex Heat Exchangers Leveraging Additive Manufacturing," Propulsion Safety and Sustainment Conference, Phoenix, AZ, May 2017. 
[10] M510 Series - Data Sheet [Online] June 2017, http://www.micropumps.co.uk/DATA/pdf/DS05\%20\%20M500\%20Data\%20Sheet\%20REV\%206\%20small.pdf

[11] Integral Rotary Integral Stirling 1/2W Micro Cooler K508N [Online] June 2017, http://www.ricor.com/products/integral-rotary/k508n/

[12]3MTM NovecTM 7000 Engineered Fluid [Online] June 2017,

[13] Sunada, Eric, and Rodriguez, Jose, "JPL Advanced Thermal Control Technology Roadmap," Spacecraft Thermal Control Workshop, El Segundo, CA 2017.

[14] Aeroglaze $\quad$ Z306 2018 Polyurethane https://www.lord.com/sites/default/files/Documents/TechnicalDataSheet/AEROGLAZE\%20Z306\%20TDS.pdf

[15] DT 670 Silicone Diodes [Online] July 2018, https://www.lakeshore.com/products/Cryogenic-TemperatureSensors/Silicon-Diodes/DT-670/Pages/Overview.aspx

[16] Flir Lepton Thermal IR Cores [Online] June 2018, https://www.flir.com/products/lepton/

[17] CompactDAQ Systems [Online] July 2018, http://www.ni.com/en-us/shop/compactdaq.html

[18] C\&R Technologies [Online] July 2018, https://crtech.com/products/thermal-desktop

[19] Pump Affinity Laws [Online] August 2018, https://en.wikipedia.org/wiki/Affinity_laws 